\title{
Conserving Marine Fishes
}

\author{
Jack Randall
}

Few marine fishes are endangered. But exotic introductions can be a serious threat to native species, especially around isolated islands such as the Hawaii group, where 30 per cent of the world's reef and shore fishes are endemic. Overfishing, pollution, destruction such as dynamiting coral reefs, and collecting for the enormous and expanding trade in aquarium fishes are the other factors. Marine sanctuaries, says the author, who is Chairman of the SSC Marine Fishes Group, are vitally important as both refuges and breeding grounds.

Very few species of marine fishes appear to be endangered, for two reasons. Firstly, most marine fishes have enormous reproductive potential. Exceptions are the elasmobranchs and a few groups of bony fishes such as the surfperches Embiotocidae, cusk eels and brotulas Ophidiidae. Other fishes either lay very large numbers of pelagic eggs or lay a smaller, but still very large number of demersal eggs with correspondingly higher chance of survival. Examples are the parental care of nests by damselfishes Pomacentridae and gobies Gobiidae; attaching eggs to floating seaweed, as by flyingfishes Exocoetidae; oval incubation by cardinalfishes Apogonidae; and production of a repellant substance in the ova, as by the cabezone Scorpaenichthys marmoratus.

Secondly, many marine fishes are widely distributed. By contrast, freshwater fishes are often confined to one river system or lake, or even to a single spring. Having so limited a range, in an environment where adverse change is always possible, they are much more likely to become endangered. Although a marine fish species may be seriously depleted in one area, it may be little affected elsewhere in its range, and the depleted area can be repopulated. Even when a population is depleted throughout its range, as was the case with the California sardine Sardinops caerulea, due in part to intensive fishing, the species survives. Long before the species is endangered, it is no longer economically feasible to continue fishing. Such species may, however, never recover their dominant position in the ecosystem, even long after fishing ceases. In some cases they are effectively replaced by other fish species; in the

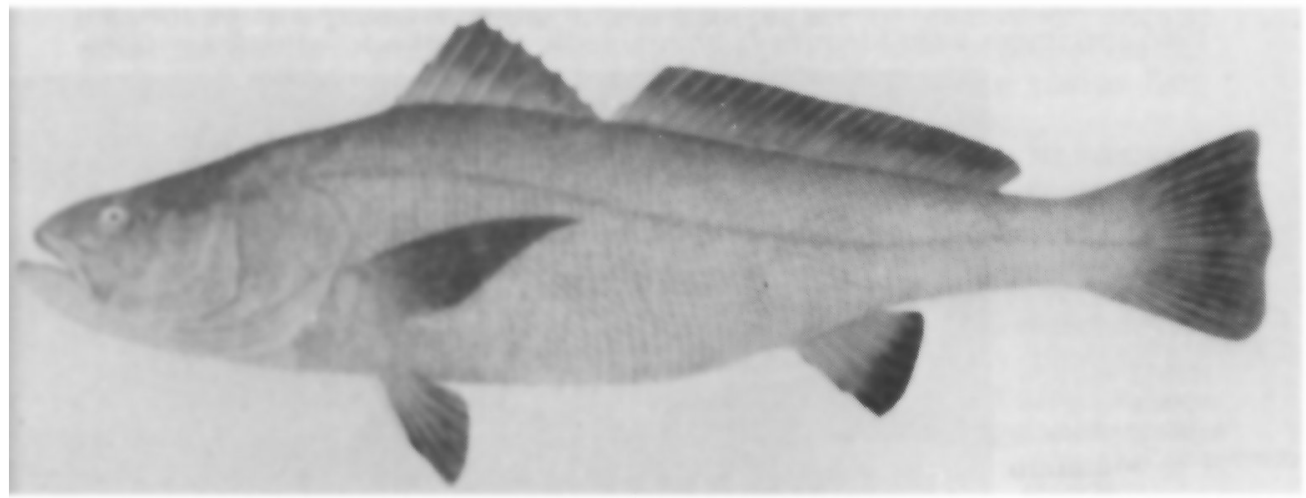


Latimeria chalumnae, a coelacanth caught off

South Africa in 1938 when it was believed that this archaic group had been extinct for 60 million years (after Smith 1940)

case of the sardine by the Pacific anchovy Engraulis mordax.

Among the few species of marine fishes that are perhaps endangered is the totuava Cynoscion macdonaldi, a large croaker of considerable commercial importance which aggregates for spawning at the mouth of the Colorado River and is thus highly vulnerable to Mexican fishing, and the Key silverside Menidia conchorum, which lives in small brackish ponds in South Florida and is threatened by drastic alteration or even elimination of its habitat. We cannot be sure that other marine species of fish are not endangered, particularly those in restricted brackish or hypersaline environments.

Many marine fish species became extinct long before man had any impact on the sea. There may now be species on the verge of extinction and man might, knowingly or not, be hastening this process in some cases. A possible example is the last known survivor of the coelacanth line, Latimeria chalumnae. The first specimen, caught by trawl off South Africa in 1938, appears to have been a stray because several others have been captured subsequently near the Comoro Islands, north-west of Madagascar. The scientific demand for this unique species, which has resulted in special efforts by local fishermen to catch specimens, may well be accelerating its approach to extinction.

The greatest threat to the survival of marine fishes is thought, however, to be the introduction of exotic species, particularly to isolated insular regions. An example is provided by the Hawaiian Islands, where 30 per cent of the world's identified reef and shore fishes are endemic. In 1955 the State government introduced the Marquesan sardine Sardinella marquesensis to the area. The sardines were caught in seines in the Marquesas and brought in the bait well of a vessel to Hawaii. In the same well were individuals of four species of jacks, of the bonefish Albula vulpes and of the small commercially valueless mullet Chelon engeli; all were dumped alive into the sea. The bonefish and jacks already occurred in Hawaii, but the mullet was not then known in the area. In 1966 specimens were identified, undoubtedly the survivors of progeny from

Chelon engeli, a small mullet introduced in Hawail and now increasing at the expense of some commercially valuable species

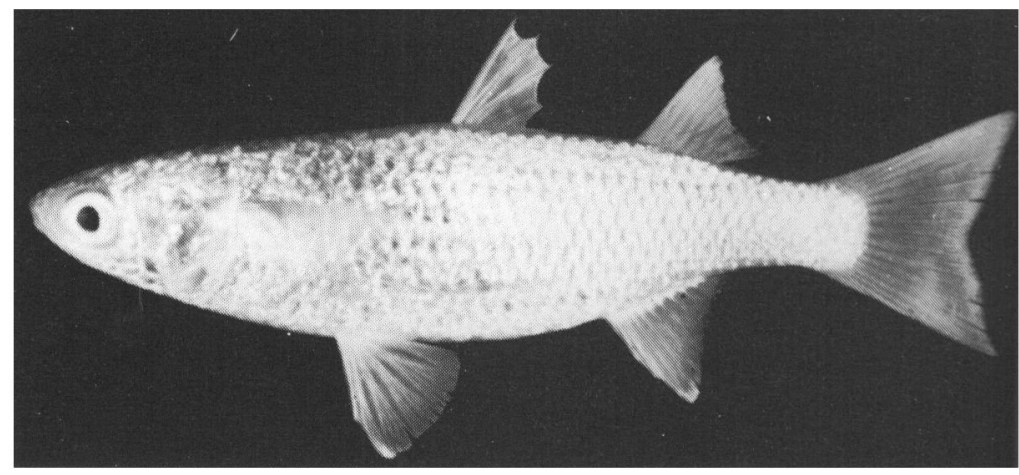


Lutjanus kasmira, a small blue-striped yellow snapper deliberately introduced in Hawaii, where it outcompetes more valuable native fishes (underwater photo J. Randall)

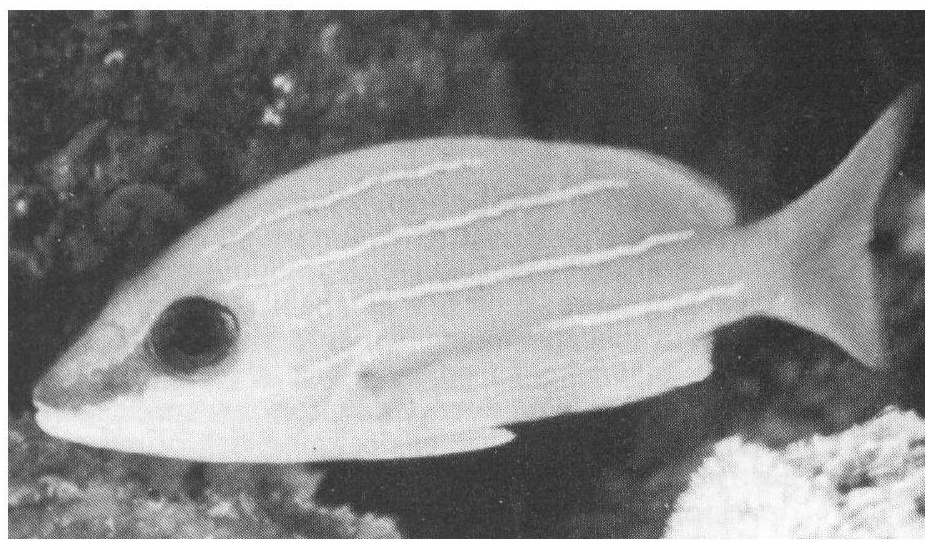

the unintentional introduction. Soon it became apparent that Chelon engeli was affecting the population of Mugil cephalus, the commercially important and highly esteemed local mullet for which a pond fishery existed at Molokai in ancient times. Now, when juvenile mullet are taken in seines, in order to obtain $M$. cephalus for ponds culture, $C$. engeli dominates the catch instead. It might eventually completely replace $M$. cephalus locally, although in this case the result would not be a species extinction because $M$. cephalus has a worldwide distribution in subtropical seas.

The Hawaiian Islands have no native shallow-water groupers of the genera Epinephelus or Cephalopholis or snapper of the genus Lutjanus. Perhaps the larval life of these fishes is too short for them to be carried by ocean current the vast distances that separate this archipelago from areas where these valuable food fishes abound. The Hawaii Division of Fish and Game introduced several species of these fishes from French Polynesia beginning in 1956, and three have become established: Cephalopholis argus, Lutjanus fulvus and L. kasmira. ${ }^{1}$ The last-mentioned snapper was a poor choice because of its small size (rarely exceeding $30 \mathrm{~cm}$ ) and because it has undergone a population explosion in Hawaiian waters, undoubtedly at the expense of some fishes of greater value than itself. It is not confined to shallow water but is abundant also at depths well over $100 \mathrm{~m}$. Hook-and-line fishermen seeking large deep-water snapper of the genera Pristipomoides and Etelis complain bitterly when they catch small L. kasmira or have their bait stolen by this species.

There are relict species in Hawaii (and at other remote areas such as Easter Island), such as the masked angelfish Genicanthus personatus, the most primitive member of the genus, which may be surviving because superior competitors have not yet colonised Hawaii. If such a competitor, or perhaps a highly effective predator, were introduced, either by chance or intent, extinction of the primitive species could result. The introduction of exotic species may mean also the threat of deleterious effects on native fish populations from parasites and diseases that are not host-specific.

Thus, the introduction of single exotic species to a small insular area can have considerable effect. And potential extinctions would be enormously multiplied if two major faunal areas of the world, the tropical eastern Pacific and Western Atlantic, were joined by a sea level canal across Central America.

Although species extinction as a result of human depredation is very much less likely for marine than for freshwater species, drastic population declines as a result of unrestrained or poorly managed fishing are increasingly common. In earlier years these were mainly of favoured demersal species groups, such as pleuronectids, but in recent years formerly enormous pelagic populations such 
as clupeoid and scombriform species have been depleted.

Apart from overfishing, pollution and other destructive practices, such as the dynamiting of reefs, have an obvious impact on fish populations, especially of reef and shore species. When habitat is destroyed, the community structure is often irrevocably changed. Sectors of coral reef that have taken millennia to develop may be reduced to rubble in seconds by explosives, and many years later only rubble may remain, with a few species of small fishes amongst it.

Sometimes the cause of declining fish populations is not so evident. The destruction of mangroves or sea-grass beds for land reclamation or harbour development often results in the loss of nursery grounds of important fishes that occur as adults in other environments. Repeated trawling over mud and sand flats, particularly with the larger and heavier gears used today, may kill the juveniles of the commercial fishes being sought, or their food or their food organisms, or may even alter their habitats. The accumulation in larger carnivores of contaminants such as DDT and mercury may or may not cause mortality of these fishes or affect their populations, but in any event it prevents them being used for human consumption.

So little is known of the interactions with the other animals and plants of a community, especially of a community as complex as a coral reef, that prediction of the consequences of altering any of the population of the community or of the environment is practically impossible. In 1968 at Onna Point, Okinawa, the wrasse Labropsis manabei, until then known from only two types of specimens, was found to be common in reefs at $20-30 \mathrm{~m}$ deep. In the same area, several years later the starfish Acanthaster planci had killed nearly all the corals; the dead coral still afforded shelter for some fishes, but $L$. manabei had been eliminated, although it survived in the southern part of the island where living corals still flourished. Observations at that time of its feeding on coral polyps readily explained its absence from the regions of the dead coral. Today the corals all round Okinawa have been killed by the starfish, and $L$. manabei and other other obligate coral feeders, such as certain butterflyfishes Chaetodon spp. cannot be found. The population explosion of Acanthaster in such localities as Okinawa, Guam and the Great Barrier Reef has been ascribed to chemical pollution (Randall, 1972), affecting not the adult reef organisms directly, but the predators of the pelargic larvae of the starfish.

In recent years coral reef fishes have been taken in increasing numbers by divers for the rapidly expanding trade in marine aquarium fishes. Collectors argue, perhaps rightly, that their take of fishes should not be considered different from that of commercial or sport fishermen. Nevertheless, they have been strongly opposed by some who maintain that the numbers of colourful fishes at favourite diving-snorkeling sites have been reduced. One resolution of such controversy is the creation of marine sanctuaries at the favourite diving sites.

Marine sanctuaries serve another very important purpose: to sustain a breeding reservoir, the larvae from which are a source of recruitment to adjacent sectors that may be subject to depletion by one cause or another. The conservation value of sanctuaries in the seas, not only for the protection of diving sites and critical inshore habitats, but also for maintaining stocks of commercially important coastal fishes, has not been generally realised. Establishment of marine parks has proved difficult in many countries, particularly because of uninformed opposition by fishermen. Marine 
sanctuaries are especially important for marine biological research, provided such research does not involve destructive techniques. Studies of the normal behaviour of fishes, unmodified by harassment from spear fishermen, are particularly useful.

A comment should be made about the vulnerability of groupers and seabasses Serranidae, which are valuable food fishes. They take a hook readily, and most species are easily approached underwater by spearfishermen. As carnivores, the larger species are near the top of the 'pyramid of numbers', hence naturally occur in relatively low numbers. They are believed to grow rather slowly, in general. Most are proterogynous hermaphrodites, starting their mature life as females and switching to males when older. With greater fishing effort to catch the larger individuals, the normal sex ratio is altered and the reproductive potential of a population substantially lowered. With all these adverse factors working together, the larger serranid fishes can be literally 'fished out' of an area. They may not be endangered as species over their entire range, but the depletion in a specific region must have a profound effect on the community as a whole.

\section{Reference}

1. RANDALL, John E., and KANAYAMA, 1972. Sea Frontiers, 18,3.

Dr John E. Randall, Bernice P. Bishop Museum, P.O. Box 19000 A, Honolulu, Hawaii 96819.

The author is Senior Ichthyologist at the Museum.

\section{Underwater Notices in a US Marine Reserve}
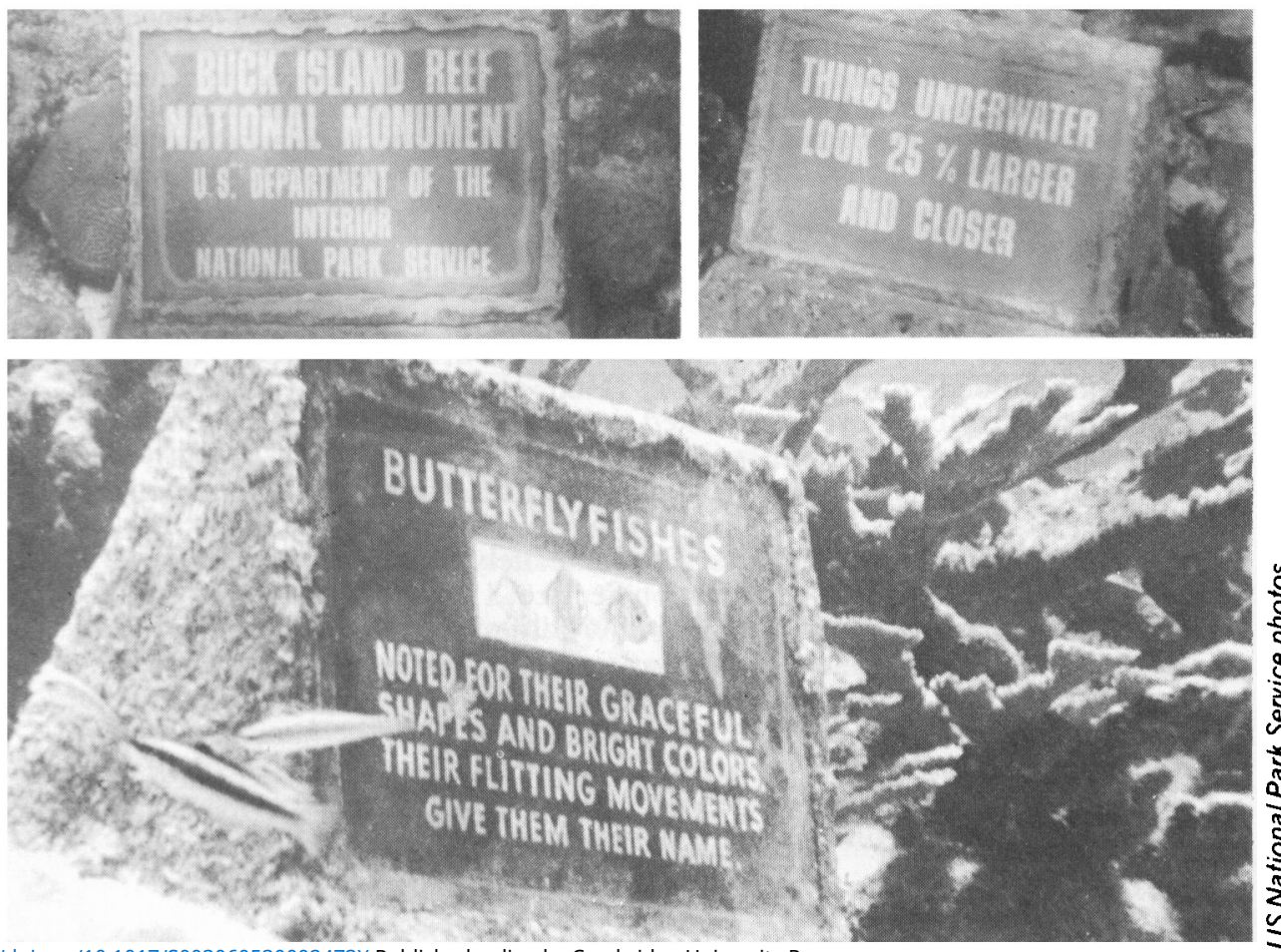